\title{
ASSESSMENT OF DIFFERENT MANAGEMENT SCENARIOS TO CONTROL SEAWATER INTRUSION IN UNCONFINED COASTAL AQUIFERS
}

\author{
Mohammed S. Hussain ${ }^{1, *}$, AKBAR A. JAVAdi ${ }^{2}$ and Mohsen M. SHerIF ${ }^{3}$ \\ ${ }^{1}$ University of Duhok, Civil Engineering Department, Duhok, Kurdistan Region-Iraq \\ ${ }^{2}$ Dept. of Engineering, University of Exeter, Exeter, UK. \\ ${ }^{3}$ Dept. of Civil and Environmental Engineering, United Arab Emirates University, Al Ain, UAE \\ * Corresponding author
}

\begin{abstract}
The present study examines the capability of different hydraulic barriers to control seawater intrusion in coastal aquifer systems. Different management scenarios including abstraction of intruded saline water near the coast, artificial recharge of the aquifer with the good quality water, and combination of abstraction and recharge are simulated in unconfined aquifers and optimally analyzed using a simulation-optimization (S/O) approach. In each scenario of control, the trade-off between two objective functions: minimization of costs of management processes and minimization of total amounts of salinity in the aquifer, was obtained using the developed $\mathrm{S} / \mathrm{O}$ framework. The recharge is implemented using a surface basin and therefore unsaturated flow theory is utilized in the simulation. Comparison of the developed management models suggests that the pumping of brackish water near the coast and its use for human and industrial consumption after desalination is an efficient method to control saltwater intrusion in deep aquifers. However, for aquifers with shallow hydrogeological settings, a new combined methodology is found to be the most cost-effective method in controlling saltwater intrusion. In this combined approach, the recharge by pond water is coupled with continuous pumping of intruded saline water near the coast followed by its desalination and use.
\end{abstract}

KEYWORDS: Seawater intrusion; Hydraulic barriers; Multi-objective optimization; Unsaturated zone.

\section{INTRODUCTION}

Qeawater intrusion (SWI) is one of the most challenging environmental problems that threatens the quality and availability of groundwater in coastal aquifers. It is considered as the outcome of the density-dependent interaction between freshwater and seawater and is responsible for the dynamic equilibrium of groundwater movement (Hussain and Javadi, 2016). In theory, the SWI process is conceptualized by two hydraulic approaches: sharp-interface and the variable-density approaches. In the sharp interface approach, the two liquids (seawater and freshwater) are considered as two immiscible fluids separated by an interface without the possibility of mixing or flow across the interface. This is the main approach used in the majority of the analytical simulations. The Ghyben-Herzberg theory is the first analytical formulation of SWI that allows a quick estimation of the equilibrium location of freshwater/seawater interface below the water table. Simplicity and low computational burden are the factors that encouraged a group of researches to use sharp interface approach (e.g. Shamir and Dagan, 1971; Mercer et al., 1980;
Essaid, 1990; Finney et al., 1992; Emch and Yeh, 1998; Bear, 1999). However, application of this approach to real problems is limited to some regular and simple aquifer geometries with several simplifying assumptions. Alternatively, and in order to simulate this mechanism, some studies have been oriented towards numerical methods to solve complex equations of variable-density groundwater flow with solute transport. In last few decades, due to the rapid developments in computer technology and numerical methods, the variable-density approach has been used extensively in numerical simulation of the process. A general overview of the available computer models for simulation of SWI is given by Sorek and Pinder (1999), Bear and Cheng (2010), Simmons (2010) and Werner et al. (2013). In the variable-density approach the hydrodynamic dispersion process controls the mixing process between these two fluids, which is more realistic and its results are closer to the actual physical behavior of aquifer systems than the sharp interface theory.

The exploitation of groundwater in aquifers causes lowering of the freshwater potentiometric level around pumping wells. The change in 
gradient in the aquifer accelerates the progressive landward invasion of the seawater, and accordingly, results in deterioration of the chemical quality of groundwater (Howard, 1987; Hussain et al., 2015c). Therefore, remedial measures have to be taken to control further degradation of the water quality in coastal aquifers. Sustainable management of water resources in coastal areas can be facilitated through the use of different arrangements and different external sources or sinks. Bruington (1972) and Todd (1974) list different methodologies that seek to manage and control SWI and to restore the quality of groundwater in aquifers. Relocation of abstraction wells, reduction of pumping rates, use of subsurface physical barriers, artificial recharge using a surface/subsurface basin and/or injection wells, abstraction of intruded saline water, and a combination of these techniques are amongst the possible control measures that can be employed (Hussain et al., 2015c; 2016).

It is necessary to use integrated optimization tools and simulation models to explore optimal solutions in a wide search space of design variables. The majority of previous studies on the optimal management of SWI considered simplified sharp interface theory, integrated with optimization tools (e.g. Emch and Yeh, 1998; Mantoglou et al., 2004; Mantoglou and Papantoniou, 2008; Papadopoulou et al., 2010; Ataie-Ashtiani and Ketabchi, 2011). The linking of sharp interface models to the optimization tools are easier because they have less complexity (Sreekanth and Datta, 2010). However, in the last decades, some 2D and 3D variable-density models (e.g. Qahman et al., 2005; Bray and Yeh, 2008; Dhar and Datta, 2009; Kourakos and Mantoglou, 2011; Javadi et al., 2012; 2015) and meta models (e.g. Das and Datta, 1999; Bhattacharjya and Datta, 2009; Dhar and Datta, 2009; Sreekanth and Datta, 2011; Kourakos and Mantoglou, 2013; 2015a; Hussain et al., 2015b) have been developed and combined with optimization tools to optimally identify and evaluate different SWI management approaches. Generally, the common objective functions which have been used in previous studies include the maximization of pumping rates while minimizing the amount of extracted salt, minimization of the total injected water, and maximization of total pumping from inland abstraction wells while minimizing the pumping from the barriers on the sea boundary.
Singh (2015) summarized the available literature on the use of $\mathrm{S} / \mathrm{O}$ processes in management of SWI in coastal aquifers.

To the authors' knowledge, the effects of the unsaturated zone on the general response of aquifer systems have not been considered in previous studies of the assessment of SWI management using simulation optimization $(\mathrm{S} / \mathrm{O})$ procedures. This may be due to the additional computational complexity resulting from the numerical simulation of the unsaturated zone simultaneously with the underlying saturated layers. This complexity is even more paramount within the S/O process in terms of computational time requirements. In addition, the cost-benefit analysis of the control process (as an important component of any management strategy) is another factor that has often been ignored in the majority of previous studies. This study aims to address these gaps in the research by considering the effects of unsaturated flow and also the recharge of aquifers using a pond system in the simulation model that is integrated with an optimization tool. To this end, the multi-objective optimization model NSGAII is linked with the SUTRA simulation model. It seemed that among the more advanced evolutionary algorithms that have been recently developed to solve multi objective problems the Non-Dominated Sorting GA (NSGA-II) has the highest popularity in the all fields of water resources management. This is one of the reasons for selecting this algorithm in the developed S/O framework. Also, NSGA-II is characterized by three significant features: (i) using the nondominated sorting algorithm that reduces the computational complexity, (ii) using the elitism preserving process for capturing the Pareto fronts, and (iii) preserving the diversity of the solutions using crowding-distance operator. The term elitist means that it keeps the best solutions during the evolution process.

The developed $\mathrm{S} / \mathrm{O}$ framework is used to assess the efficiencies of different arrangements of hydraulic barriers to control SWI in unconfined coastal systems. Recharge by a surface pond, abstraction of brackish water, and combined abstraction and recharge are the three management methods considered in this work. The objective functions include the minimization of the total economic cost of management methods and also the minimization of the total amount of salt in the aquifer. During this process, the optimal location and depth of abstraction well and location of 
recharge pond and rates of abstraction/recharge in each method are assessed. In addition, by considering the unsaturated flow in the vadose zone, different schemes are examined for each method. For methods which concern recharge, the treated wastewater (TWW) is adopted as a reliable and economic source of water for artificial recharging of aquifers. The inherent benefits associated with the use of this reclaimed source of water in artificial recharge include substantial recovery of groundwater levels, offsetting the seasonal variations in water supply, improvement of aquifer water quality, and control of SWI ( $\mathrm{Li}$ et al., 2006). Finally, the study attempts to evaluate the effects of the thicknesses of the unsaturated and saturated layers on the optimal results of the management methods.

\section{METHODOLOGY}

The NSGAII optimization tool is integrated with a numerical code (SUTRA) to optimize different arrangements considered to control the encroachment of seawater. The finite element model (SUTRA) was developed by Voss and Provost (2010) to simulate 2D/3D saturatedunsaturated, variable-density groundwater flow with solute or energy transport. Simulation of unconfined aquifers under saturated/unsaturated flow conditions is a more realistic option, especially for systems subjected to artificial or natural surface recharge. In these simulations, the distribution of water pressure and the rate of recharge are controlled by the hydrogeological properties of the vadose zone. Although, this factor has not been considered in the majority of previous studies, the present work addresses this problem by modeling flow through saturated/unsaturated zones. In this study, van Genuchten's model (1980) for describing the water retention characteristics of soil is used to simulate the unsaturated flow in the vadose zone. This is done by the specification of saturation $(S)$ as a function of pressure $(p)$ :

$$
\begin{aligned}
& S=S_{r e s}+\left(1-S_{r e s}\right)\left(\frac{1}{1+\left(\alpha p_{c}\right)^{n}}\right)^{m} \\
& \frac{d S}{d p}=\left(\frac{\alpha(n-1)\left(1-S_{r e s}\right)\left(\alpha p_{c}\right)^{(n-1)}}{\left[1+\left(\alpha p_{c}\right)^{n}\right]^{(1+m)}}\right)
\end{aligned}
$$

$$
k_{r}=S^{*(1 / 2)}\left(1-\left[1-S^{*(1 / m)}\right]^{m}\right)^{2}
$$

Equation (1) presents the relationship between the degree of saturation with capillary pressure $p_{c}$ and residual degree of saturation $S_{\text {res }}$ and equation (2) presents this relationship in a differential form (Voss and Provost, 2010). Equation (3) presents the relationship for relative permeability $k_{r}$ as a function of degree of saturation. $\alpha, n$, and $m$ are the fitting parameters, $m=1-(1 / n)$ and $S^{*}$ is the relative degree of saturation equal to $\left(S-S_{\text {res }}\right) /(1-$ $\left.S_{r e s}\right), k_{r}$ can be predicated from the water retention curve.

Generally, the management of coastal aquifers is a complex multi-objective process. Therefore, the use of multi-objective optimization would be more appropriate than conventional methods with single objective function. In a multi-objective optimization there usually exist a set of solutions (Pareto front), which cannot simply be compared with each other (Gen and Cheng, 2000). The simulation model (SUTRA) is linked with NSGAII, a well-known multi-objective genetic algorithm, to identify the optimal solutions for the proposed management methods. In the developed S/O framework, the numerical model is repeatedly called by NSGAII to calculate state variables (pressures and concentrations) in response to each set of generated design variables. The process starts by creating a random population of decision variables of size $\mathrm{N}$ and computing their state variables in the numerical model. After evaluating the fitness of the objective functions, the main processes (selection, crossover, and mutation) of genetic algorithm are performed to generate offspring population of decision variables. As a consequence, the corresponding state variables and the objective functions are evaluated. Then, the Elitism process is commenced by combining the populations of parents and children (mating pool) followed by ranking and selecting the individuals based on non-dominated sorting principles. All the individual members of the nondominated front of parents and children are copied to the new parent population rank by rank. The process of adding in the rank is stopped when the size of the parent population exceeds the population size N. However, in order to maintain diversity in the population, the solutions (individuals) in the last accepted rank are sorted 
by the crowding distance sorting algorithm. In this way the new parent population with size $\mathrm{N}$ is created and generates offspring for the next generation. The new values of decision variables are then returned to SUTRA and the selection, crossover and mutation, and elitism processes are repeated until optimality criteria are satisfied and finally the trade-off curve of optimal solutions is captured (Deb et al., 2002). The flow chart of the $\mathrm{S} / \mathrm{O}$ algorithm is shown in Figure 1.

\section{APPLICATION}

An unconfined aquifer with dimensions $200 \mathrm{~m}$ by $100 \mathrm{~m}$ is used as a 2D hypothetical case study to evaluate the developed S/O framework (Figure 2). The model is discretized using 2600 quadrilateral elements and 2706 nodes. Freshwater and seawater pressure boundaries of the aquifer are specified by assigning hydrostatic water heads for the left and right boundaries of the model. In the model an unsaturated layer overlies a saturated layer. The bottom boundary of the aquifer is assumed to be impermeable to water and solute. The main input data used for the simulation model are: $0.0 \mathrm{mg} / \mathrm{l}$ and $35700 \mathrm{mg} / \mathrm{l}$ salinity for inflow boundaries of freshwater respectively. It should be noted that this amount of seawater salinity (i.e. $35700 \mathrm{mg} / \mathrm{l})$ is equivalent to $0.0357\left(\mathrm{~kg}_{\text {solute }} / \mathrm{kg}_{\text {fluid }}\right)$ mass fraction. The applied transverse and longitudinal dispersivities are $0.5 \mathrm{~m}$ and $5.0 \mathrm{~m}$ respectively. Also, $1.0 \times 10^{-9} \mathrm{~m}^{2} / \mathrm{s}$ for coefficient of water molecular diffusion ; 0.3 for porosity, 43 $\mathrm{m} /$ day for hydraulic conductivities of the saturated and $0.22 \mathrm{~m} /$ day unsaturated zones are considered. For the simulation of the unsaturated flow, residual saturation (0.23) and fitting parameters $\alpha$ $\left(2 \times 10^{-4} \mathrm{~m} . \mathrm{s}^{2} / \mathrm{kg}\right)$ and $n(1.3)$ are used in the van Genuchten model (1980). A fine spatial discretization is used for the unsaturated layer. Also, in order to converge and limit the oscillatory results of the numerical calculations, the system is discretized with a time step of 0.02 days (Voss and Provost, 2010). To obtain the natural initial values of pressure within the domain, first a steady state solution was obtained through an extra simulation with 20000 time steps. Figure 3 illustrates the result of salinity distribution through the system in steady state condition and under the above mentioned boundary conditions. The total calculated mass of solute entering the aquifer was 92 tons at steady state condition. Moreover, to simulate a plan for future demand, a production well pumping fresh water with a constant rate of $26 \mathrm{~m}^{3} /$ day at a location $40 \mathrm{~m}$ from the inland boundary and at a depth of $70 \mathrm{~m}$ is incorporated into the model. The location of the production well and the corresponding steady state salinity distribution of the model under this pumping condition is shown in Figure 4. The results in Figure 4 show that the aquifer and the planned production well are threatened by seawater intrusion. In order to alleviate this problem, a management action is required to be taken to comply with the planned demand for water supply while protecting the aquifer against SWI. 


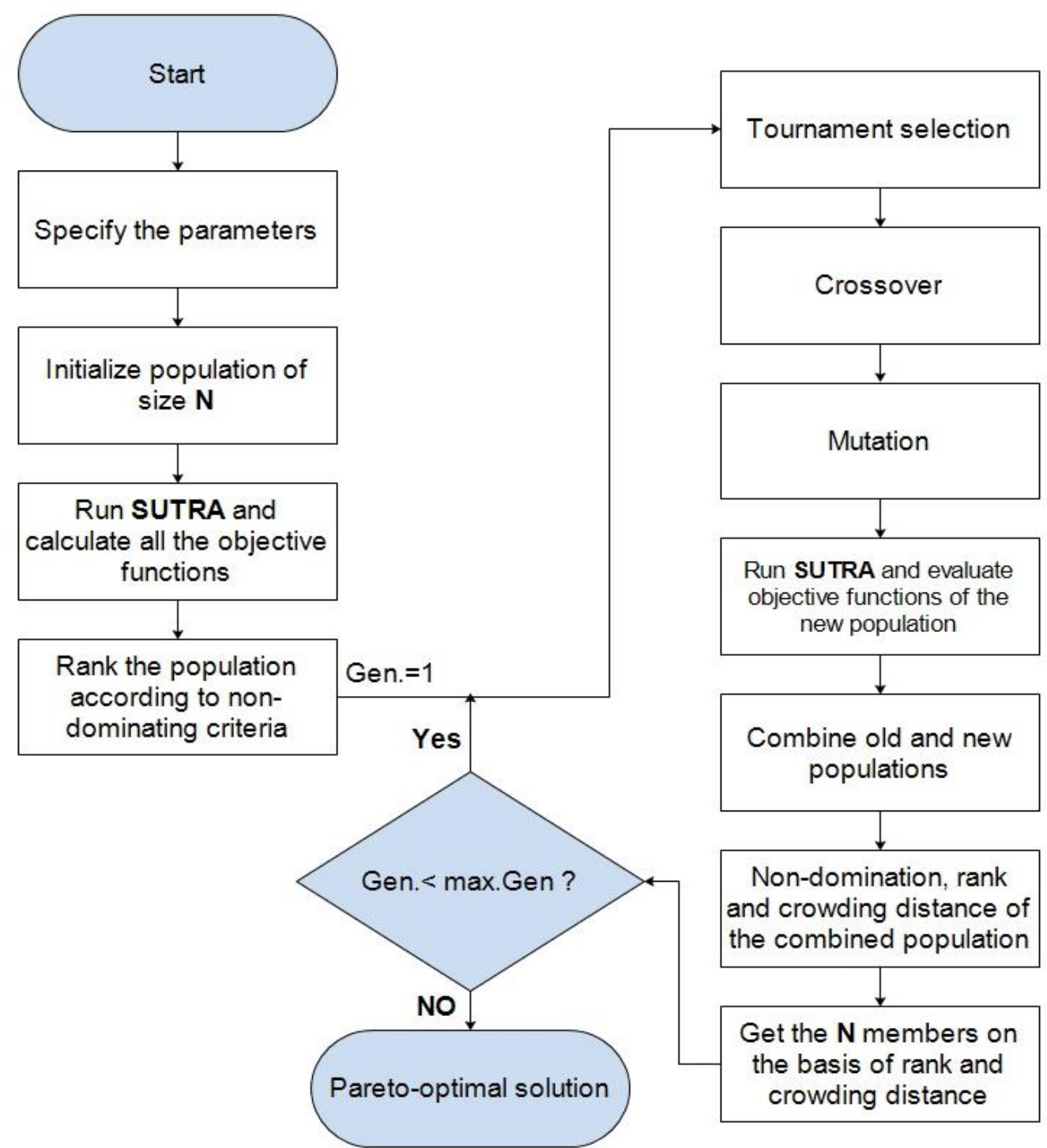

Fig. (1): Flow chart of the simulation-optimization model.

\section{Landside}

-hydrostatic pressure

-solute mass fraction $=0.0$
Seaside

-hydrostatic pressure -solute mass fraction $=0.0357$

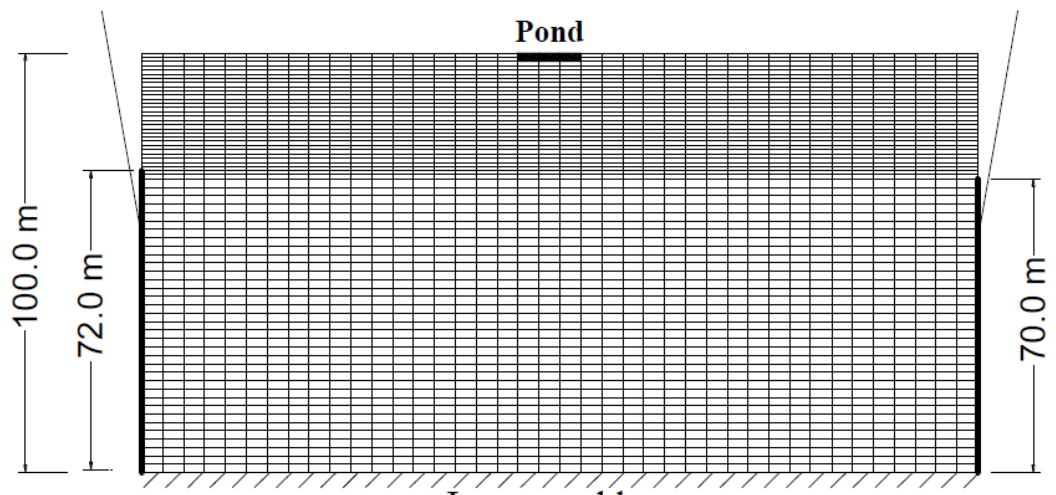

Impermeable

Fig. (2): Model geometry and the used boundary conditions. 


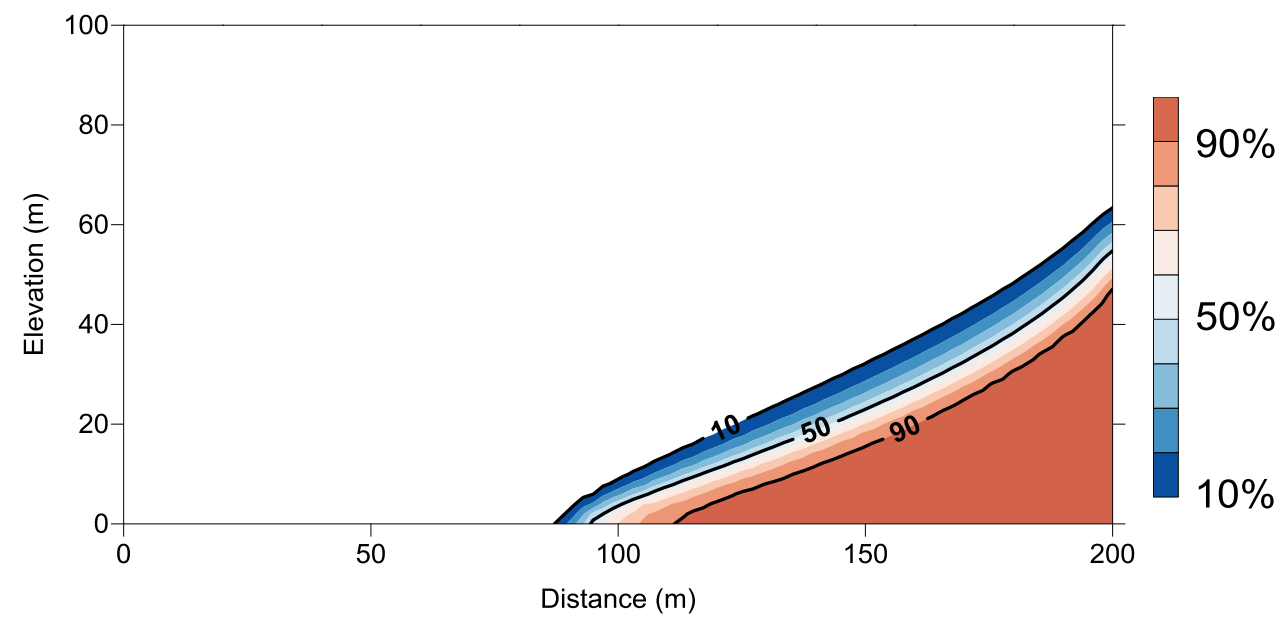

Fig. (3): Natural variation of concentration through the system in steady state condition (\%).

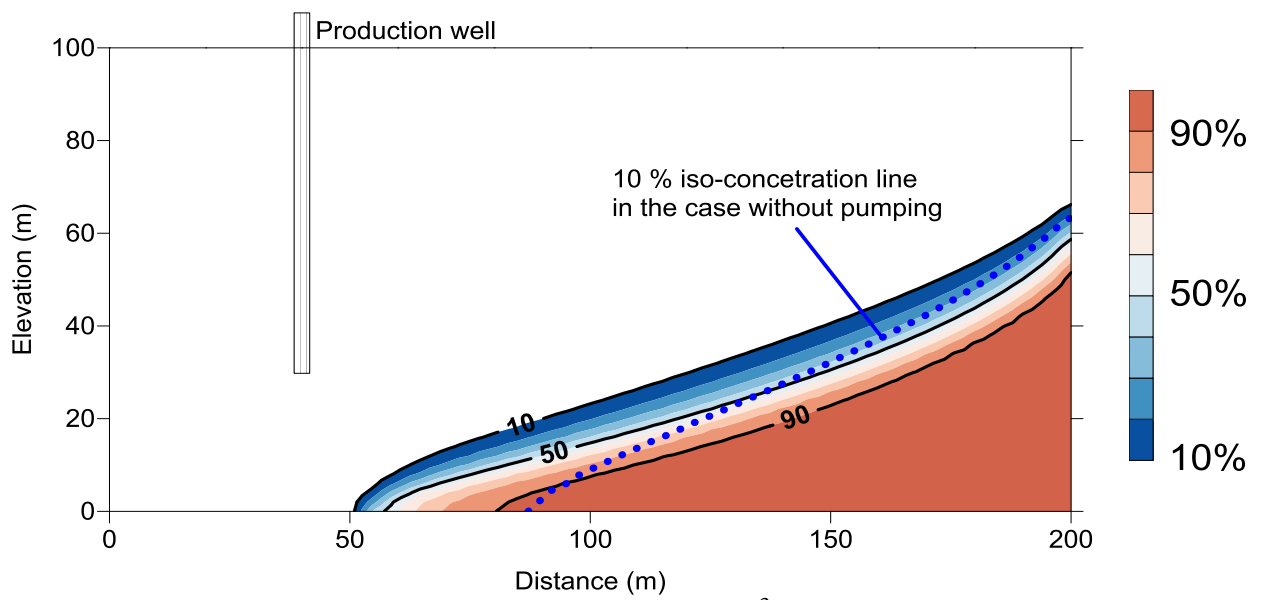

Fig. (4): Steady state distribution of salinity due to $26 \mathrm{~m}^{3} /$ day pumping from production well (\%).

\section{FORMULATION OF OPTIMIZATION MODELS}

A number of management models are considered to restrict the damage caused by the saline intrusion wedge during pumping of freshwater from the production well. These models involve different arrangements of hydraulic barriers in the aquifer. The control models are optimally assessed in terms of economic and environmental benefits. The system is subjected to three different control scenarios: i) recharge only, ii) abstraction only, and iii) a combined system of abstraction and recharge. The recharge is carried out through a surface basin to allow collected water to infiltrate into the aquifer. The performance of each scenario in terms of controlling SWI is investigated in different schemes. The technique aims to minimize the two conflicting objective functions: total mass of solute present in the aquifer (total $\mathrm{C}$ or $f_{l}$ ) and the total operational and construction cost of the management process $\left(f_{2}\right)$. Hence, the general forms of the objective functions and constraints for this aquifer can be expressed mathematically as

follows:

$$
\begin{aligned}
& \min f_{1}=\sum_{i=1}^{N} C_{i} v_{i} \\
& \min f_{2}=\text { Managment } \operatorname{Cos} t=f\left(Q r, Q a, R C, A C, T C, P C, D C, P M C, \alpha_{1}, \alpha_{2}, r, \Delta t\right) \\
& \text { subject to: }
\end{aligned}
$$

$0<X r(m)<200$ 
$0<Q a\left(m^{3} /\right.$ day $)<52$

$0<X a(m)<200$

$30<D a(m)<100$

Total mass of solute $<92$ tons

where $\mathrm{N}$ is the total number of nodes in the finite element mesh, $\mathrm{C}_{\mathrm{i}}$ is the concentration of the solute at node $\mathrm{i}, \mathrm{v}_{\mathrm{i}}$ is the volume of finite element cell at node i, Qa and Qr are abstraction and recharge rates $\left(\mathrm{m}^{3} / \mathrm{sec}\right), \mathrm{Xa}$ and $\mathrm{Xr}$ are the horizontal distances of the abstraction well and recharge pond from the sea boundary, respectively, and $\mathrm{Da}$ is the depth of the abstraction well (m). $R C, A C$, $T C$, and $D C$ are the costs of artificial recharge by the pond $\left(\$ / \mathrm{m}^{3}\right)$, abstraction $\left(\$ / \mathrm{m}^{3}\right)$, treatment $\left(\$ / \mathrm{m}^{3}\right)$, and installation/drilling of the well $(\$ / \mathrm{m})$ respectively. $P C$ is the cost of the construction of the pond (\$), $P M C$ is the cost of cleaning and maintenance of the pond $(\$)$, and $\alpha_{1}\left(\$ / \mathrm{m}^{3}\right)$ and $\alpha_{2}$ $\left(\$ / \mathrm{m}^{3}\right)$ are market prices of desalinated water and reclaimed TWW, respectively. $r$ is the recovery ratio of the desalination plant and $\Delta t$ is the duration of the application of the management strategy. The total management cost $\left(f_{2}\right)$ is calculated based on the following typical unit costs: $D C$ (\$200 per unit depth), $A C\left(\$ 0.42 / \mathrm{m}^{3}\right)$, $R C\left(\$ 0.12 / \mathrm{m}^{3}\right), T C\left(\$ 0.6 / \mathrm{m}^{3}\right), \alpha_{1}\left(\$ 1.5 / \mathrm{m}^{3}\right), \alpha_{2}$ $\left(\$ 0.25 / \mathrm{m}^{3}\right)$, and $P C$ for a pond with dimensions $15 \mathrm{~m} \times 2 \mathrm{~m} \times 1 \mathrm{~m}(\$ 350)$. The $P M C$ is assumed to be $10 \%$ of the construction cost (Chen et al., 2003; Asano and Bahri, 2010; Abazza, 2012; Isaka, 2012; Javadi et al., 2012). The design variables considered in the simulation-optimization model are summarized in Figure 5.

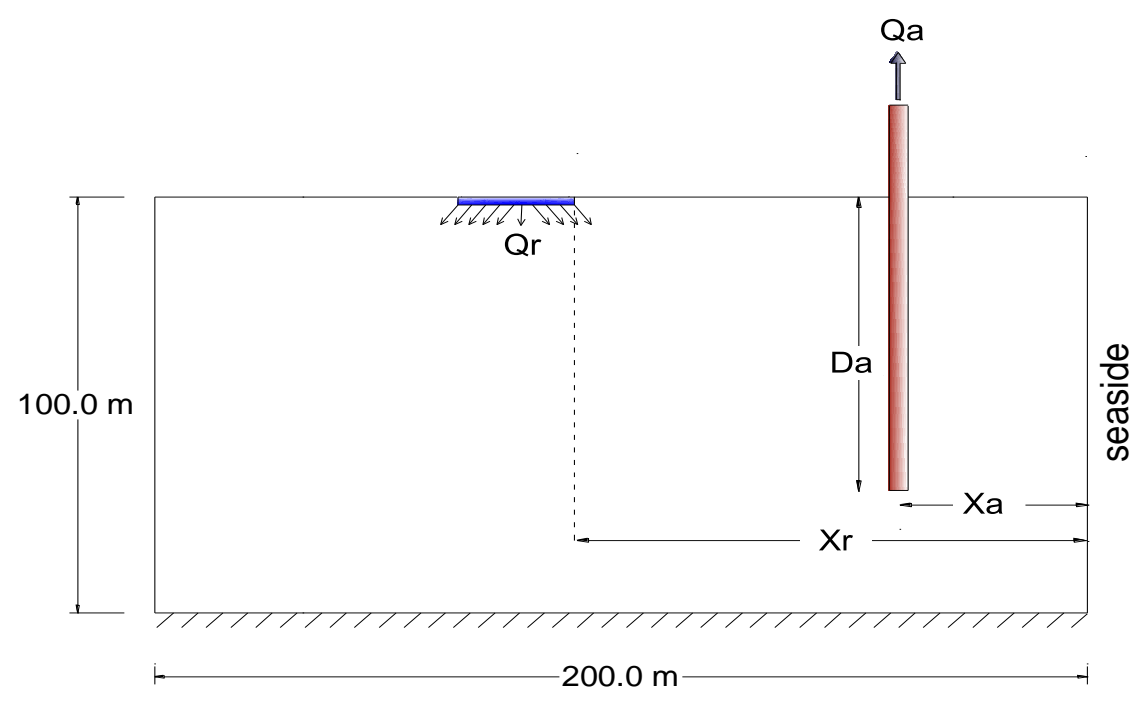

Fig. (5): Schematic sketch for the decision variables.

\subsection{Management model I (recharge scenarios)}

This management model is designed to maintain (and increase) the seaward hydraulic gradient of water using recharge trough surface pond to control SWI. Two different scenarios are considered in this management model. In the first one, the aquifer is recharged by the excess of desalinated water, while in the second it is recharged by treated wastewater (TWW). The cost objective function $\left(f_{2}\right)$ with relevant constraints for this model can be derived from equation (5) as: 
1- Recharge by excess of desalinated water

$\min f_{2}=Q r *\left(R C+\alpha_{1}\right) * \Delta t+P C+P M C$

2- Recharge by treated wastewater

$\min f_{2}=Q r *\left(R C+\alpha_{2}\right) * \Delta t+P C+P M C$

The total dissolved solids considered for desalinated water is $250 \mathrm{mg} / \mathrm{l}$ and for TWW it is $1300 \mathrm{mg} / \mathrm{l}$. Artificial recharge is implemented by designing a surface pond $15 \mathrm{~m}$ long and $2 \mathrm{~m}$ deep. The average rate of recharge directly under the pond is $0.35 \mathrm{~m} /$ day, which is calculated by SUTRA. Based on this constant rate of recharge, and as shown in equations $11 \mathrm{a}$ and $11 \mathrm{~b}$, the cost function $\left(f_{2}\right)$ in each of these two scenarios will have a fixed value. Therefore, the number of objective functions of the recharge scenarios is reduced to one. Accordingly, in these scenarios the horizontal location of the artificial infiltration basin $(X r)$ is the only decision variable; therefore, the optimal value of the total solute mass in the system $\left(f_{l}\right)$ can be evaluated by changing $X r$ along the length of the domain and numerically calculating the corresponding values of $f_{l}$ instead of S/O optimization (Figure 6). The optimal location of the pond $(\mathrm{Xr})$ is found to be between $65 \mathrm{~m}$ and $95 \mathrm{~m}$ from the shoreline.

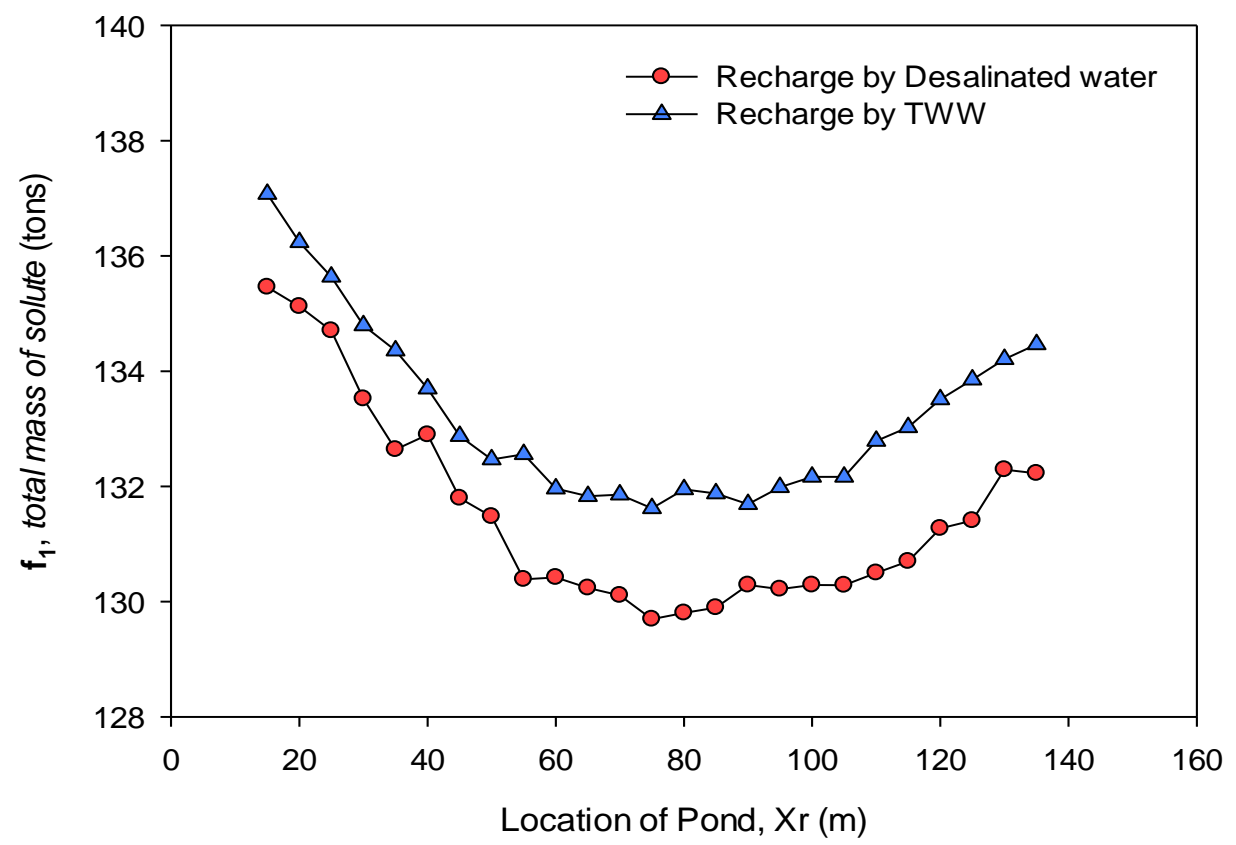

Fig. (6): Variations of total concentration in the system with the pond location in the recharge scenarios.

\subsection{Management model II (abstraction scenarios)}

In this model, the brackish water is continuously abstracted from the saline zone. This results in lowering of water levels near the coastal boundary, improving the seaward gradient of groundwater, and reducing the total amount of saline intrusion in the aquifer. The cost function has a direct relationship with the optimal rate of pumping and the location and depth of the abstraction well. Therefore, as shown in Figure 5, $X a, D a$, and $Q a$ are the decision variables of this scenario and the numerically calculated state variables are pore pressure and solute concentrations. This model is also assessed through two different scenarios, (i) abstraction followed by desalination and (ii) abstraction followed by direct disposal in the sea. In the first approach, the abstracted water is desalinated to provide an additional source of water to meet part 
of the demand. Therefore, the cost of desalination and the benefit gained from the value of this desalinated water are included in the cost function. However, by considering the recovery ratio of desalination plants, considerable amounts of abstracted water which feed the desalination plant will be rejected and leave the system as concentrated brine. Depending on the feed water quality, typical recovery ratios vary from 50 to $80 \%$ for brackish water (and 20 to $40 \%$ for seawater) using standard reverse osmosis plants (Singh, 2013). Consequently, this ratio is also considered in the cost function of the first scenario of model II. The net cost function $\left(f_{2}\right)$ of the process is represented by equation (12a).

The second scenario involves the cyclic process of abstraction of brackish water from the saline wedge and its direct disposal in the sea. This process can locally restrict the encroachment of seawater in the coastal boundary. Equation (12b) expresses the mathematical form of the cost function for this method. The multi-objective optimization of these abstraction scenarios, subjected to the side constrains (equations 7-10), can be expressed as:

1- Abstraction and desalination

$\min f_{2}=D a * D C+Q a *(A C+T C) * \Delta t-Q a$

2- Abstraction and disposal in the sea

$\min f_{2}=D a * D C+Q a * A C * \Delta t$

\subsection{Management model III (combined scenarios)}

This management model combines the efficiencies of management models I and II in controlling SWI. Based on the optimal results obtained for the location of the pond in management model I (Figure 6), the location of the recharge basin $(X r)$ in the combined scenarios is fixed at a distance of $95 \mathrm{~m}$ from the sea boundary in order to guarantee the maximum efficiency of the recharge system. Therefore, in this management model three decision variables are considered, namely location, depth, and abstraction rates of the barrier well. The three different scenarios considered for this model are i) abstraction of saline water followed by desalination and recharging of the aquifer with the excess of the desalinated water (ADR), ii) abstraction of saline water followed by desalination and recharging of the aquifer with TWW (ADRTWW), and iii) abstraction of saline water and direct disposal in the sea followed by recharging of the aquifer with TWW (ASRTWW).

ADR was proposed by Javadi et al. (2012) as an effective method for controlling the encroachment of seawater and for enhancing the total productivity of coastal aquifer systems. The methodology is based on the continuous pumping of brine and highly concentrated brackish water near the shoreline and desalination of the abstracted water using an appropriate desalination model such as reverse osmosis (Greenlee et al., 2009). The excess of the produced desalinated water can then be utilized as a source of water to recharge the aquifer while the rest of the treated water is used to meet part of the water demand (Javadi et al., 2012). In ADR, the desalinated water is injected into the deep aquifer by recharge wells. However, in the present study, surface ponds are used to collect the excess of desalinated water and recharge the aquifer. The cost function for the new ADR scenario used in the present work is represented by equation (13a). By including the recovery ratio $(r)$ and market prices of desalinated water $\left(\alpha_{1}\right)$ in the function, the net benefit from the value of the desalinated water is calculated and included in the equation.

In the second scenario of management model III a new methodology, ADRTWW, is developed where the abstracted brackish water is desalinated and used, while reclaimed (treated) wastewater is used for artificial recharge. Although this TWW contains a greater salinity than desalinated water, it helps to retard the saline water by increasing the seaward gradient of water heads. The cost of this new source of recharge is included in the relevant equation (13b) as the $\alpha_{2}$ term. Finally, in the third scenario (equation 13c) the abstracted water is directly disposed in the sea and an external source of reclaimed wastewater (TWW) is used for groundwater recharge. 


\section{1- ADR}

$\min f_{2}=Q r * R C * \Delta t+D a * D C+Q a *(A C+T C) * \Delta t-(r * Q a-Q r) * \alpha_{1} * \Delta t+P C+P M C$

\section{2- ADRTWW}

$\min f_{2}=Q r *\left(R C+\alpha_{2}\right) * \Delta t+D a * D C+Q a *(A C+T C) * \Delta t-Q a^{*} r^{*} \alpha_{1}^{*} \Delta t+P C+P M C$

3- ASRTWW

$\min f_{2}=Q r *\left(R C+\alpha_{2}\right) * \Delta t+D a * D C+Q a * A C * \Delta t+P C+P M C$

\section{RESULTS AND DISCUSSION}

The optimal results in the three scenarios considered are derived by employing the S/O model for a management period of 10 years. These scenarios involve continuous abstraction of freshwater from the production well with a constant rate of $26 \mathrm{~m}^{3} /$ day. A recovery ratio of $60 \%$ is assumed for desalination of brackish water. The following parameters are used by NSGAII: total number of generations is 100 , population size is 50, and probabilities of crossover and mutation are 0.9 and 0.0025 , respectively.

Recharge scenarios: Artificial recharge develops a "freshwater ridge" in order to reduce, stop or even reverse the lowered levels of water and protect the system against SWI (Luyun et al., 2011). The results for the recharge scenario show that the cost of recharge by reclaimed wastewater is $\$ 7386$, which is about a quarter of the cost of the recharge by desalinated water (\$31040) owing to the lower market value of reclaimed wastewater compared with desalinated water. The artificial groundwater recharge by desalinated water, which contains a lower content of total dissolved solids results in better control on saltwater intrusion and further repulsion of the saline water wedge than recharge by reclaimed TWW. Both scenarios generally fail to control the total mass of solute in the aquifer below the indicated value (92 tons for natural steady state condition).

Abstraction scenarios: The trade-off curves obtained for this management model are shown in Figure 7a. Both scenarios of this management model successfully control SWI. However, the abstraction of brackish water followed by desalination is more efficient compared with the cases of direct disposal of the withdrawn saline water in the sea. According to the trade-off curves, the range of optimal location and depth of pumping well and rate of pumping are $20-65 \mathrm{~m}$, $92-96 \mathrm{~m}$, and $6.5-45 \mathrm{~m}^{3} /$ day, respectively, for the first scenario and $15-65 \mathrm{~m}, 92-98 \mathrm{~m}$, and $6.5-$ $52 \mathrm{~m}^{3} /$ day, respectively, for the second scenario. According to the trade-off curve the optimal pumping rates follow an increasing trend with the seaward movement of the abstraction well. The inclusion of the monetary value of the desalinated water as a benefit in the management process is a key factor in the success of the first scenario.

Recharge+Abstraction: All three scenarios proposed in this management model show their capability to optimally control SWI (Figure 7b). Along the trade-off line, the optimal ranges for $X a, D a$, and $Q a$ are 20-50m, 84-98m and 9$41 \mathrm{~m}^{3} /$ day, respectively, for the ADR scenario, 15 $50 \mathrm{~m}, 84-96 \mathrm{~m}$, and $9-52 \mathrm{~m}^{3} /$ day, respectively, for ADRTWW, and 20-65m, 94-98m, and 5$41 \mathrm{~m}^{3} /$ day for the combined scenario ASRTWW. In terms of minimizing the total cost and salinity concentration, the results indicate that the second scenario (ADRTWW) offers a significantly greater efficiency than the other scenarios. This is because ADRTWW allows to use all of the desalinated water as an additional source of fresh water. In contrast, comparison of the results indicates that the first scenario of management model II (abstraction + desalination) has the best performance among all three scenarios. 


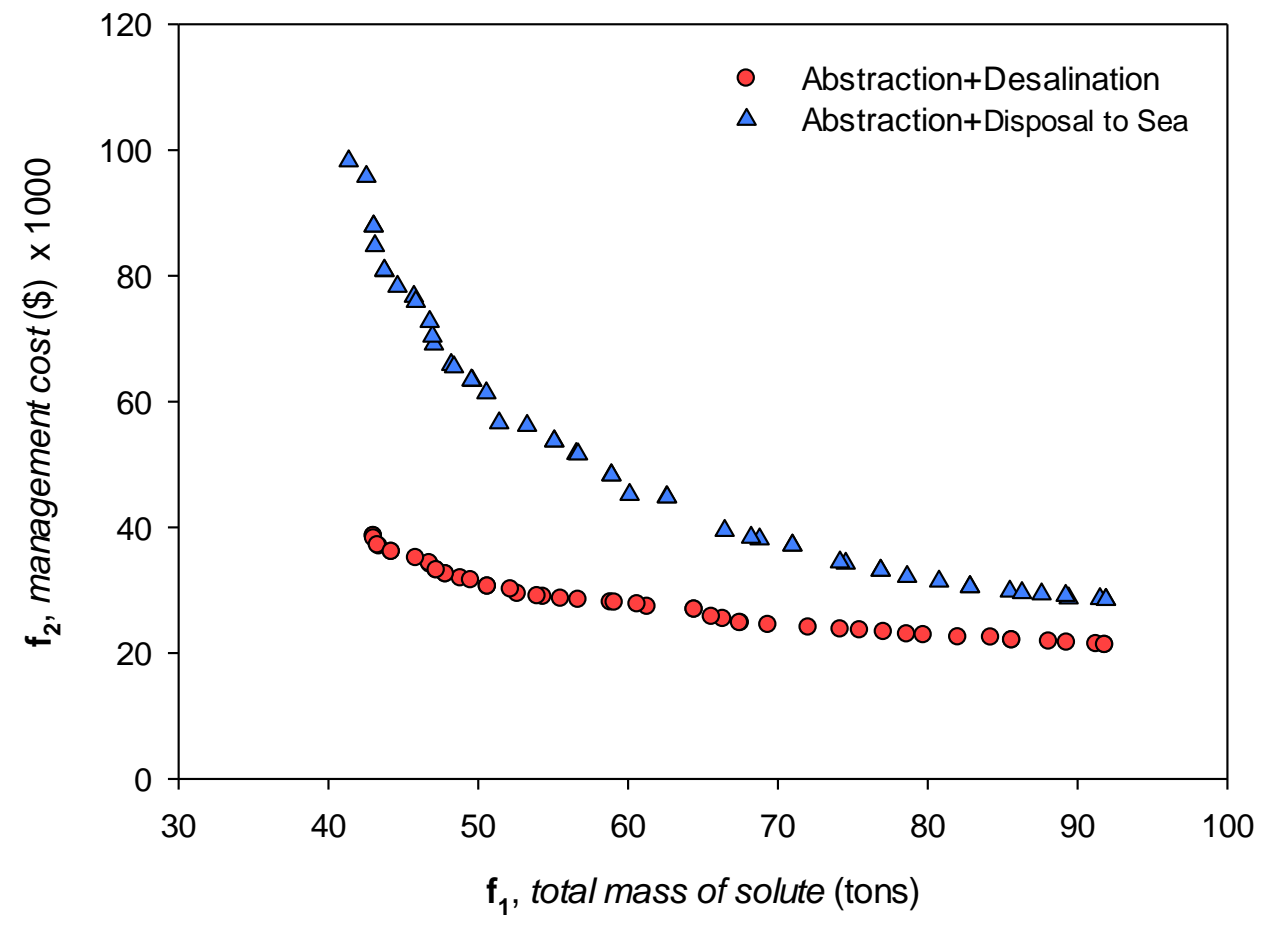

(a)

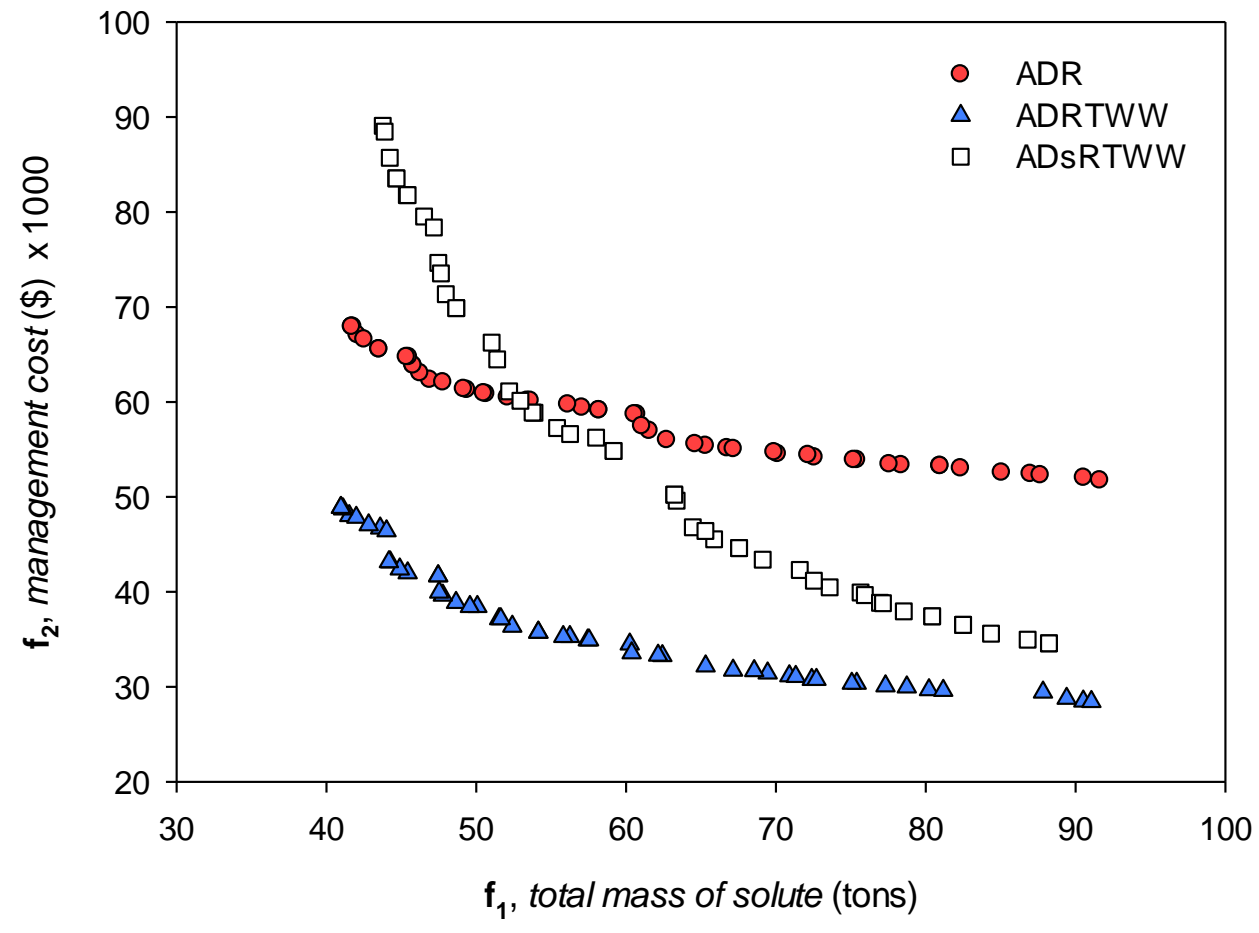

(b)

Fig. (7): Optimal trade-off curves of a) abstraction and b) combined (abstraction+ recharge) scenarios. 


\section{SENSITIVITY ANALYSIS}

\subsection{Effects of unsaturated zone thickness on optimal solutions}

In order to study the effect of the depth of the vadose zone $(d z)$, the aquifer is modified to include a thin layer of unsaturated zone. The new model has a total thickness of $80 \mathrm{~m}$. All the other boundary conditions and simulation parameters remain the same as before, subjected to same rate of abstraction from the production well. The Pareto fronts of this new model with a thin layer of unsaturated zone $(d z \approx 10 \mathrm{~m})$ are determined for the first scenario of model II and ADRTWW and the results are compared with those of an aquifer with a thicker vadose zone $(d z \approx 30 \mathrm{~m})$, as illustrated in Figures 8. Despite the positive effects of the new system (aquifer with $d z \approx 10 \mathrm{~m}$ ) on the optimal results in both management cases, the ADRTWW again fails to surpass the efficiency of the first scenario of the abstraction scenario. Accordingly, utilization of recharge by the surface pond only and in combined scenarios is not recommended for aquifers with a thicker unsaturated zone.

The aquifer considered in this study has a relatively large saturated thickness. This zone is in direct contact with the saline water body which can result in greater penetration at the saltwater/freshwater interface. Therefore, the illustrated recharge system does not have the capability to repel this large quantity of intruded saline water even if the thickness of the unsaturated zone is small. This suggests that further study of the efficiencies of the developed management processes in unconfined aquifers with thinner saturated layers is necessary.

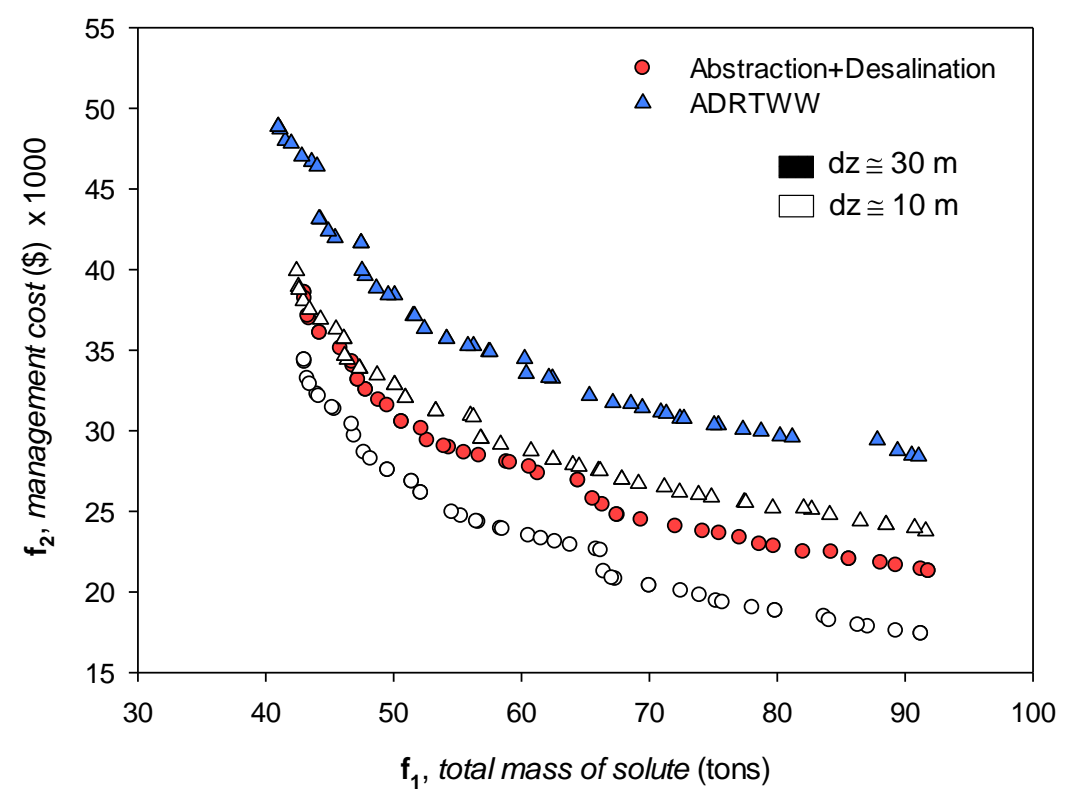

Fig. (8): Effects of thickness of unsaturated layer on Pareto fronts of abstraction only and ADRTWW scenarios.

\subsection{Effects of saturated zone thickness on optimal solutions}

For this section of the study, the geometry of the aquifer is modified to impose $31 \mathrm{~m}$ and $30 \mathrm{~m}$ of hydrostatic pressure on the inland and seaside boundaries, respectively. The thickness of the vadose zone is about $10 \mathrm{~m}$. The system is simulated under the same rate of pumping from the production well and under the same boundary conditions as for the reference model. The total calculated mass of intruded solute in the system is 27 tons and 98 tons prior to and after pumping, respectively. The Pareto fronts of this new aquifer with a thin saturated layer are calculated using the developed S/O framework for the first case of model-II and ADRTWW scenarios, as shown in Figure 9. The results highlight that ADRTWW is significantly more efficient in terms of minimizing 
the total cost and salinity. Consequently, the ADRTWW management methodology is recommended to control SWI in relatively small, unconfined aquifers. In order to examine the capability of this scenario, the final steady state distributions of salinity throughout the system are presented in Figure 10 for the three optimal solutions (marked as S1, S2, and S3 in Figure 9). These solutions are selected along the Pareto front based on engineering judgment in terms of the objective functions. Their performances in controlling SWI are compared with nomanagement scenario. The optimal locations of pumping well are determined as $10 \mathrm{~m}, 15 \mathrm{~m}$, and $20 \mathrm{~m}$ from the sea boundary for these three solutions S1, S2, and S3, respectively. Also, 23.9 $\mathrm{m}^{3} /$ day, $15.5 \mathrm{~m}^{3} /$ day, and $9.9 \mathrm{~m}^{3} /$ day are the optimal rates of pumping in these selected solutions, respectively. The optimal depth of the pumping well is $37 \mathrm{~m}$ below the top boundary for all three solutions.

In summary, the economic functionality of the first scenario of the management model II (abstraction only) indicates that it is a cost effective method for deep aquifers. The study confirms previous findings that suggest the installation of deep wells for recharge in deep aquifers. Furthermore, the injection of TWW in combined scenarios could increase their efficiencies in tackling the SWI problem in deep aquifers. However, application of TWW and/or storm water coupled with continuous abstraction of brackish water and its desalination and use is the most cost effective method to control the encroachment of saltwater in small, unconfined aquifers with relatively thin saturated layers.

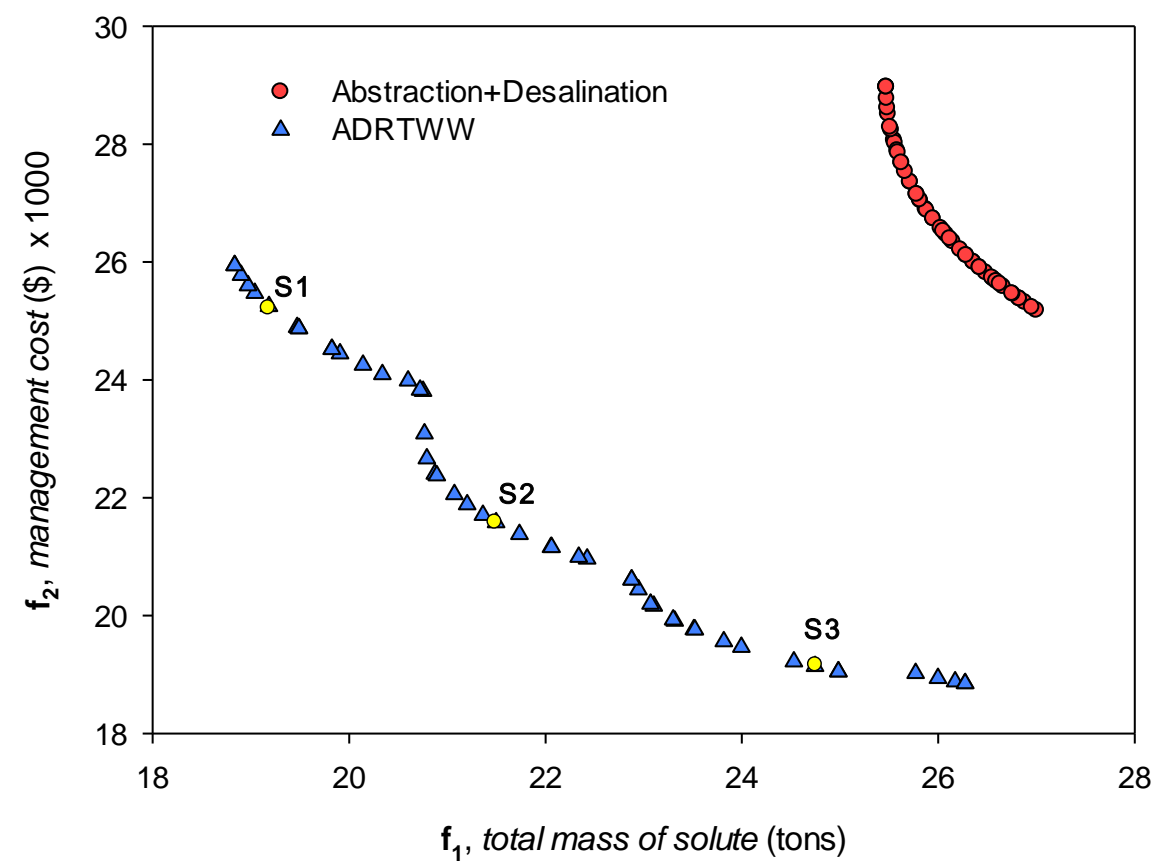

Fig. (9): Comparison of the optimal Pareto fronts in ADRTWW and abstraction only scenarios in aquifer with thinner saturated layer.

\section{CONCLUSIONS}

In an attempt to study the optimal response of unconfined coastal aquifers to different scenarios of controlling saltwater intrusion, a FE-based simulation model was linked with a multiobjective optimization tool. (i) Artificial recharge of good quality water through the spreading basin, (ii) abstraction of intruded saline water near the coast, and (iii) a combination of recharge and abstraction are the three management scenarios, which were considered and compared in different schemes of control. It was found that, in relatively small unconfined aquifers (or with small saturated layers), the proposed integrated methodology (ADRTWW) is more efficient than the other methods tested. ADRTWW involves continuous abstraction of saline water, desalination and 
recharge of the aquifer with TWW using a surface pond. This proposed methodology can control SWI with the least cost and the least amount of salinity.

\section{ACKNOWLEDGEMENTS}

Funding of a $\mathrm{PhD}$ scholarship by the Ministry of Higher Education and Scientific Research in Kurdistan Regional Government of Iraq (KRGHCDP Scholarship program) to support the first author is gratefully acknowledged.
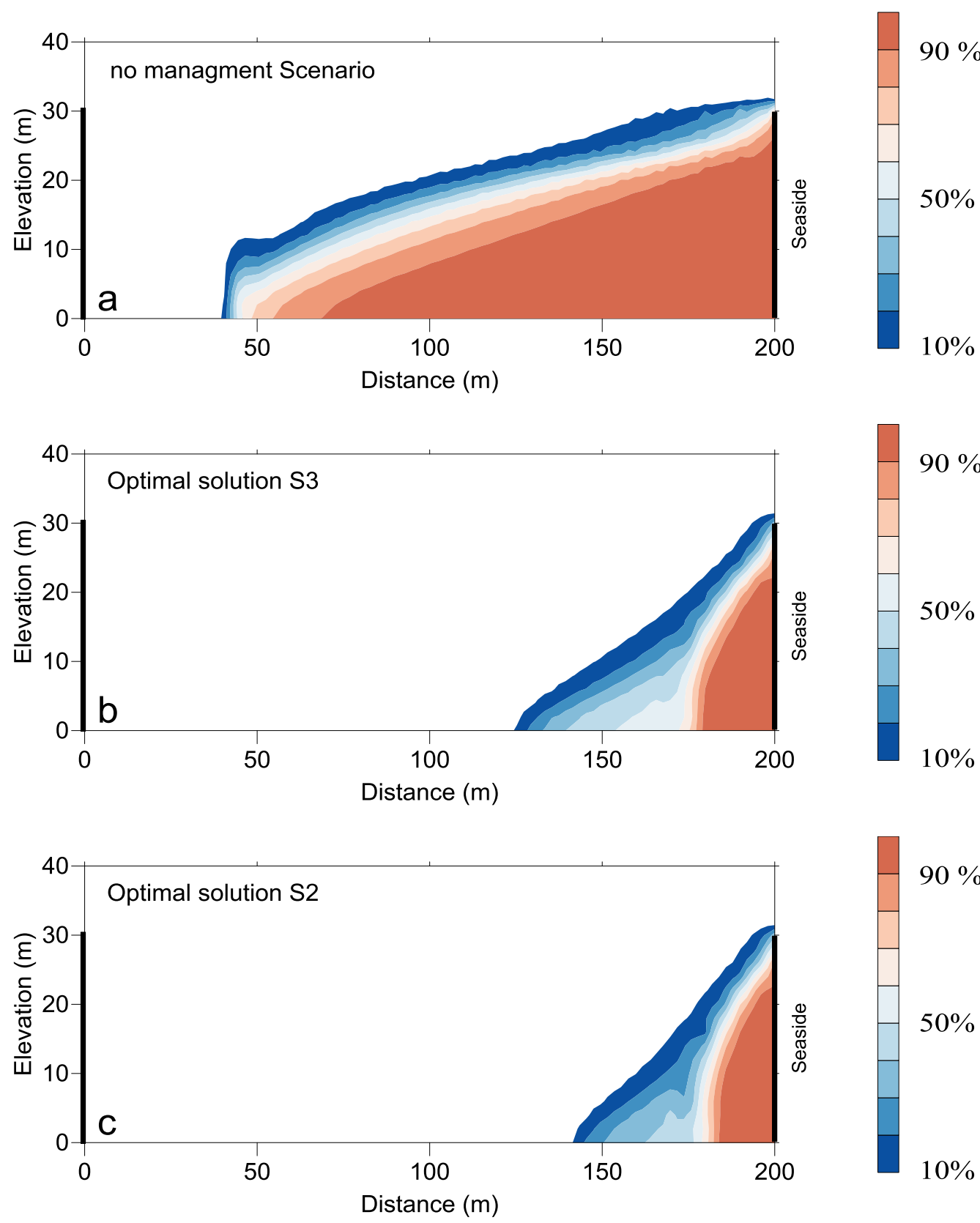

$90 \%$

$10 \%$ 


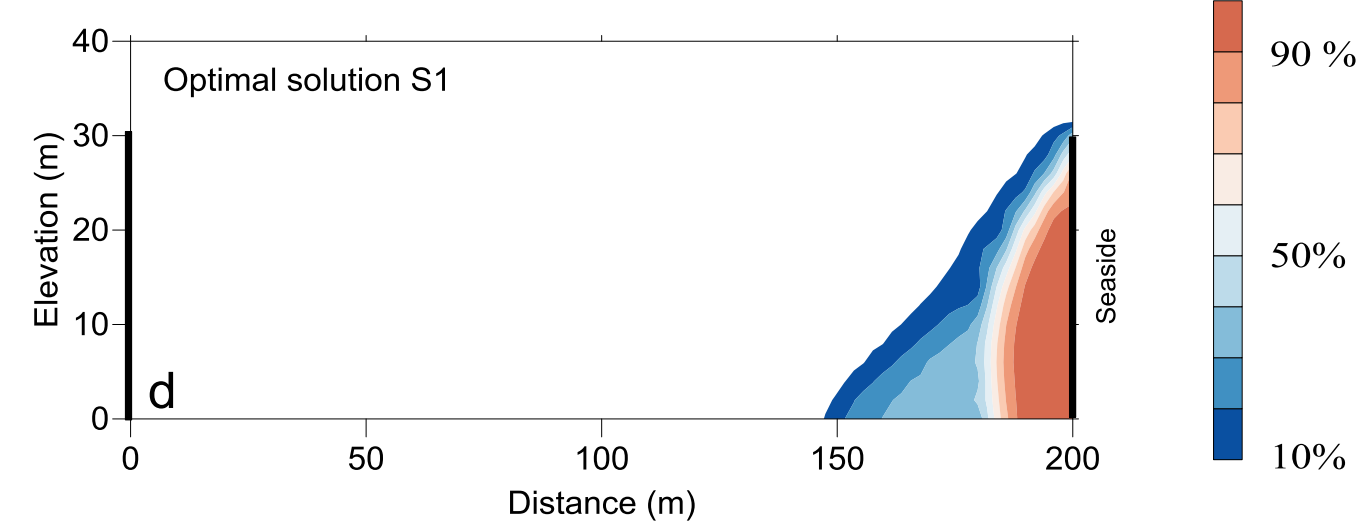

Fig. (10): Steady state salinity distribution (\%) of the system where no management is employed (a) and the three selected optimal management solutions of the ADRTWW scenario (b, c and d).

\section{LIST OF ABBREVIATIONS}

SWI Seawater Intrusion

S/O Simulation-Optimization

ADR Abstraction-Desalination-Recharge

ADRTWW Abstraction-Desalination-Recharge by TWW

ASRTWW Abstraction-Disposal to Sea-Recharge

by TWW

TWW Treated Waste Water

$f 1, f 2 \quad$ Objective Functions

NSGAII

Non-Dominated Sorting Genetic

Algorithm

$\alpha n \& m \quad$ Fitting Parameters Considered in

Unsaturated Model

$p_{c} \quad$ Capillary Pressure

$p \quad$ Pressure

$S \quad$ Degree of Saturation

$S_{\text {res }} \quad$ Residual Degree of Saturation

$k_{r} \quad$ relative permeability

$d_{z} \quad$ Thickness of Unsaturated Zone

2D, 3D Two and Three-Dimensional

N

Total Number of Nodes in the Domain of Simulation Model $v_{i} \quad$ Volume of Finite Element Cell at Node $i$

$C_{i} \quad$ Salinity at Node $i$

$X r \quad$ Horizontal Location of Pond from Coastline

$X a$ Horizontal Location of the Abstraction Well from Coastline

Da Depth of Abstraction Well

Qa Abstraction Rate

Qr Recharge Rate

$A C \quad$ Cost of Abstraction

TC Cost of Treatment

$D C \quad$ Cost of Installation/Drilling of well

$R C \quad$ Cost of Recharge using Pond System

$P C \quad$ Cost of Pond Construction

PMC Annual Cost of Cleaning and Maintenance of Pond

$\alpha_{1} \quad$ Market Price of Desalinated Water

$\alpha_{2} \quad$ Market Price of TWW

$r \quad$ Recovery Ratio of the Desalination Plant

$\Delta t \quad$ Duration of Control Scenario

\section{REFERENCES}

- Abazza, H. (2012). Economic Considerations for Supplying Water Through Desalination In South Mediterranean Countries. Sustainable Water Integrated Management-Support Mechanism (SWIM-SM).

- Asano, T., and Bahri, A. (2010). Global challenges to wastewater reclamation and reuse. Selections from the 2010 World Water Week in Stockholm, Edited by Jan Lundqvist: 64-72.

- Ataie-Ashtiani, B., and Ketabchi, H. (2011). Elitist Continuous Ant Colony Optimization Algorithm for Optimal Management of Coastal Aquifers. Water Resources Management, 25(1), 165-190. doi: http://dx.doi.org/10.1007/s11269-010-9693$\underline{x}$

- Bear, J. (1999). Conceptual and Mathematical Modeling. In J. Bear, A. D. Cheng, S. Sorek, D. Ouazar and I. Herrera (Eds.), Seawater Intrusion in Coastal Aquifers - Concepts, Methods and Practices (Vol. 14, pp. 127-161): Springer Netherlands.

- Bear, J., and Cheng, H. D. A. (2010). Seawater Intrusion Modeling Groundwater Flow and Contaminant Transport (Vol. 23, pp. 593-636): Springer Netherlands.

- Bhattacharjya, R., and Datta, B. (2009). ANN-GABased Model for Multiple Objective Management of Coastal Aquifers. Journal of 
Water Resources Planning and Management, 135(5), 314-322. doi: http://doi.org/10.1061/(ASCE)07339496(2009)135:5(314)

- Bray, B., and Yeh, W. (2008). Improving Seawater Barrier Operation with Simulation Optimization in Southern California. Journal of Water Resources Planning and Management, 134(2), 171-180.

http://dx.doi.org/10.1061/(ASCE)07339496(2008)134:2(171)

- Bruington, A. E. (1972). Saltwater intrusion into aquifers1. JAWRA Journal of the American Water Resources Association, 8(1), 150-160. doi: $\quad$ http://dx.doi.org/10.1111/j.17521688.1972.tb05104.x

- Chen, J. J., Zhou, Y., Su, Z. Y., Lin, G. R., Fu, F., Miller, P., and McCarty, D. (2003). Tertiary treatment of wastewater for reuse in China. Paper presented at the Proceedings of the Water Environment Federation,Technical Exhibition and Conference (WEFTEC), AlexandriaVirginia.

- Das, A., and Datta, B. (1999). Development of Multiobjective Management Models for Coastal Aquifers. Journal of Water Resources Planning and Management, 125(2), 76-87. doi: http://dx.doi.org/10.1061/(ASCE)07339496(1999)125:2(76)

- Deb, K., Pratap, A., Agarwal, S., and Meyarivan, T. (2002). A fast and elitist multiobjective genetic algorithm: NSGA-II. IEEE Trans Evol Comput, 6(2), 182-197. doi: http://dx.doi.org/10.1109/4235.996017

- Dhar, A., and Datta, B. (2009). Saltwater Intrusion Management of Coastal Aquifers. I: Linked Simulation-Optimization. Journal of Hydrologic Engineering, 14(12), 1263-1272. doi: http://dx.doi.org/10.1061/(ASCE)HE.19435584.0000097

- Emch, P., and Yeh, W. (1998). Management Model for Conjunctive Use of Coastal Surface Water and Ground Water. Journal of Water Resources Planning and Management, 124(3), 129-139. doi:

10.1061/(ASCE)07339496(1998)124:3(129)

- Essaid, H. I. (1990). A multilayered sharp interface model of coupled freshwater and saltwater flow in coastal systems: Model development and application. Water Resources Research, 26(7), 1431-1454. doi: 10.1029/WR026i007p01431

- Finney, B., Samsuhadi, and Willis, R. (1992). Quasi- Three- Dimensional Optimization Model of Jakarta Basin. Journal of Water Resources Planning and Management, 118(1), 18-31. doi: 10.1061/(ASCE)07339496(1992)118:1(18)

- Gen, M., and Cheng, R. (2000). Genetic algorithms and engineering optimization (Vol. 7). New York: John Wiley \& Sons.
- Greenlee, L. F., Lawler, D. F., Freeman, B. D., Marrot, B., and Moulin, P. (2009). Reverse osmosis desalination: Water sources, technology, and today's challenges. Water Research, 43(9), 2317-2348. doi: http://dx.doi.org/10.1016/j.watres.2009.03.010

- Howard, K. W. F. (1987). Beneficial Aspects of SeaWater Intrusion. Ground Water, 25(4), 398-406. doi: 6584.1987.tb02144.x

http://dx.doi.org/10.1111/j.1745-

- Hussain, M. S., Ahangar-asr, A., Chen, Y., and Javadi, A. A. (2015a). A New Evolutionary Approach to Geotechnical and GeoEnvironmental Modelling. In A. H. Gandomi, A. H. Alavi and C. Ryan (Eds.), Handbook of Genetic Programming Applications (pp. 483499): Springer International Publishing.

- Hussain, M. S., and Javadi, A. A. (2016). Assessing impacts of sea level rise on seawater intrusion in a coastal aquifer with sloped shoreline boundary. Journal of Hydro-environment Research, 11, 29-41. doi: http://doi.org/10.1016/j.jher.2016.01.003

- Hussain, M. S., Javadi, A. A., Ahangar-Asr, A., and Farmani, R. (2015b). A surrogate model for simulation-optimization of aquifer systems subjected to seawater intrusion. Journal of Hydrology, 523(0), 542-554. doi: http://dx.doi.org/10.1016/j.jhydrol.2015.01.079

- Hussain, M. S., Javadi, A. A., and Sherif, M. M. (2015c). Three dimensional simulation of seawater intrusion in a regional coastal aquifer in UAE. Procedia Engineering, 119, 1153-1160. doi: http://dx.doi.org/10.1016/j.proeng.2015.08.965

- Hussain, M. S., Javadi, A. A., Sherif, M. M., and Naseri-Karim-Vand, R. (2016). Control of saltwater intrusion by aquifer storage and recovery. Proceedings of the Institution of Civil Engineers - Engineering and Computational Mechanics, 169(3), 148-155. doi: $10.1680 /$ jencm.15.00021

- Isaka, M. (2012). Water desalination using renewable energy: International Energy Agency (IEA) and The International Renewable Energy Agency (IRENA).

- Javadi, A., Hussain, M., Sherif, M., and Farmani, R. (2015). Multi-objective Optimization of Different Management Scenarios to Control Seawater Intrusion in Coastal Aquifers. Water Resources Management, 29(6), 1843-1857. doi: 10.1007/s11269-015-0914-1

- Javadi, A. A., Abd-Elhamid, H. F., and Farmani, R. (2012). A simulation-optimization model to control seawater intrusion in coastal aquifers using abstraction/recharge wells. International Journal for Numerical and Analytical Methods in Geomechanics, 36(16), 1757-1779. doi: http://dx.doi.org/10.1002/nag.1068

- Kourakos, G., and Mantoglou, A. (2011). Simulation and Multi-Objective Management of Coastal 
Aquifers in Semi-Arid Regions. Water Resources Management, 25(4), 1063-1074. doi: http://dx.doi.org/10.1007/s11269-010-9677-x

- Kourakos, G., and Mantoglou, A. (2013). Development of a multi-objective optimization algorithm using surrogate models for coastal aquifer management. Journal of Hydrology, 479(0), 13-23.

doi: http://dx.doi.org/10.1016/j.jhydrol.2012.10.050

- Li, Q., Harris, B., Aydogan, C., Ang, M., and Tade, M. (2006). Feasibility of Recharging Reclaimed Wastewater to the Coastal Aquifers of Perth, Western Australia. Process Safety and Environmental Protection, 84(4), 237-246. doi: http://dx.doi.org/10.1205/psep.05202

- Luyun, R., Momii, K., and Nakagawa, K. (2011). Effects of Recharge Wells and Flow Barriers on Seawater Intrusion. Ground Water, 49(2), 239249. doi: http://dx.doi.org/10.1111/j.17456584.2010.00719.x

- Mantoglou, A., and Papantoniou, M. (2008). Optimal design of pumping networks in coastal aquifers using sharp interface models. Journal of Hydrology, 361(1-2), 52-63. doi: http://dx.doi.org/10.1016/j.jhydrol.2008.07.022

- Mantoglou, A., Papantoniou, M., and Giannoulopoulos, P. (2004). Management of coastal aquifers based on nonlinear optimization and evolutionary algorithms. Journal of Hydrology, 297(1-4), 209-228. doi: http://dx.doi.org/10.1016/j.jhydrol.2004.04.011

- Mercer, J. W., Larson, S. P., and Faust, C. R. (1980). Simulation of Salt-Water Interface Motion. Ground Water, 18(4), 374-385. doi: 10.1111/j.1745-6584.1980.tb03412.x

- Papadopoulou, M., Nikolos, I., and Karatzas, G. (2010). Computational benefits using artificial intelligent methodologies for the solution of an environmental design problem: saltwater intrusion. Water Science \& Technology-WST, 62(7), 1479-1490. doi: 10.2166/wst.2010.442

- Qahman, K., Larabi, A., Ouazar, D., Naji, A., and Cheng, A. D. (2005). Optimal and sustainable extraction of groundwater in coastal aquifers. Stochastic Environmental Research and Risk Assessment, 19(2), 99-110. doi: http://dx.doi.org/10.1007/s00477-004-0218-0

- Shamir, U., and Dagan, G. (1971). Motion of the Seawater Interface in Coastal Aquifers: A Numerical Solution. Water Resources Research, 7(3), 644-657. doi: 10.1029/WR007i003p00644

- Simmons, C. T., Bauer-Gottwein, P. ,Graf, T. , Kinzelbach, W.,Kooi,H. ,Li, L., Post, V.,Prommer,H. ,Therrien, R. ,Voss,C. I. ,Ward, J. ,Werner,A. . (2010). Variable density groundwater flow: from modelling to applications. In S. A. M. Howard S. Wheater and X. Li (Eds.), Groundwater Modelling in Arid and Semi-Arid Areas (pp. 87-118): Cambridge University Press.

- Singh, A. (2015). Managing the environmental problem of seawater intrusion in coastal aquifers through simulation-optimization modeling. Ecological Indicators, 48(0), 498-504. doi: http://dx.doi.org/10.1016/j.ecolind.2014.09.011

- Singh, R. P. (2013). Water Desalination" The Role of RO and MSF. IOSR Journal of Environmental Science, Toxicology And Food Technology (IOSR-JESTFT), 6(2), 61-65. doi: http://dx.doi.org/10.9790/2402-0626165

- Sorek, S., and Pinder, G. F. (1999). Survey of Computer Codes and Case Histories. In J. Bear, A. D. Cheng, S. Sorek, D. Ouazar and I. Herrera (Eds.), Seawater Intrusion in Coastal Aquifers - Concepts, Methods and Practices (Vol. 14, pp. 399-461): Springer Netherlands.

- Sreekanth, J., and Datta, B. (2010). Multi-objective management of saltwater intrusion in coastal aquifers using genetic programming and modular neural network based surrogate models. Journal of Hydrology, 393(3-4), 245-256. doi: http://dx.doi.org/10.1016/j.jhydrol.2010.08.023

- Sreekanth, J., and Datta, B. (2011). Coupled simulation-optimization model for coastal aquifer management using genetic programming-based ensemble surrogate models and multiple-realization optimization. Water Resources Research, 47(4), W04516. doi: http://dx.doi.org/10.1029/2010WR009683

- Todd, D. K. (1974). Salt-Water Intrusion and Its Control. Journal (American Water Works Association), $\quad$ 66(3), $\quad 180-187$. http://www.jstor.org/stable/41266996

- van Genuchten, M. T. (1980). A closed-form equation for predicting the hydraulic conductivity of unsaturated soils. Soil Science Society of America Journal, 44(5), 892-898. doi: http://dx.doi.org/10.2136/sssaj1980.0361599500 4400050002x

- Voss , C. I., and Provost, A. M. (2010). SUTRA-A model for saturated-unsaturated variable-density ground-water flow with solute or energy transport (pp. 300): U.S. Geol. Surv. (USGS), Water Resour. Invest.

- Werner, A. D., Bakker, M., Post, V. E. A., Vandenbohede, A., Lu, C., Ataie-Ashtiani, B., Simmons, C. T., and Barry, D. A. (2013). Seawater intrusion processes, investigation and management: Recent advances and future challenges. Advances in Water Resources, 51(0), 3-26.

doi: http://dx.doi.org/10.1016/j.advwatres.2012.03.0 $\underline{04}$ 